\title{
Comparative and Mixture Effect of Cynodon Dactylon, ElectroMagnetic Field and Insulin on Diabetic Mouse
}

\author{
Saeid Nafisi', Mohammad Ali Mohammad Nezhady², Mohammad Hossein Asghari ${ }^{1}$ \\ ${ }^{1}$ Faculty of Veterinary Medicine, Urmia University, Urmia, Iran \\ ${ }^{2}$ Faculty of Science, Islamic Azad University, Urmia Branch, Urmia, Iran
}

\section{ABSTRACT}

Objective: New investigations are in progress to find some alternative treatments for diabetes mellitus. Herbs are some of the interesting medications in this regard. Cynodon dactylon (C.d) is a potential plant to be considered as a new medication. On the other hand, the effect of the Electromagnetic Field (EMF) on bio organisms is becoming clearer. In this study, the effect of C.d, EMF and insulin have been investigated on the diabetic mouse.

Material and Methods: Diabetes was induced by a combination of ketamine $(60 \mathrm{mg} / \mathrm{Kg})$ and xylazine $(10 \mathrm{mg} / \mathrm{Kg})$ which induces a sustained hyperglycemia. Mice were divided into 12 groups: 1) control, 2) normal saline, 3 and 4) 50mg/Kg C.d, 5 and 6) $100 \mathrm{mg} / \mathrm{Kg}$ C.d, 7) insulin, 8) insulin and C.d, 9) EMF $(110 \mathrm{KHz}, 700 \pm 20 \mathrm{mG}), 10)$ insulin and EMF, 11) EMF plus C.d and 12) insulin plus C.d and EMF. Blood glucose level was measured after 5 and 60 minutes in C.d administrated groups, and 5 minutes in the other groups by a glucometer set. The data were analyzed by ANOVA and different means were compared by Tukey and Bonferroni tests $(p<0.05)$.

Results: According to results, both dosages of C.d had significant lowering effect on blood glucose level. The first dose was more effective than the second, and its impact was just like insulin. The $6^{\text {th }}, 9^{\text {th }}$ and $10^{\text {th }}$ groups were significant, also. However, they did not show a higher effect than insulin or C.d. The application of EMF had a significant effect compared to the second group, but it did not reduce the glucose level to the normal range. The effect of the $8^{\text {th }}$ group was very impressive and the mean glucose levels in this group were lower than the control group.

Conclusion: Considering the data, C.d is a good alternative medication for diabetes mellitus.

Key Words: Diabetes mellitus, cynodon dactylon, electromagnetic field, insulin, glucose

Received: 23.05.2012

Accepted: 18.09.2012

\section{Introduction}

One of the major concerns of society in health issues is diabetes. Malfunction in the metabolism of blood sugar (Glucose) leads to diabetes. This malfunction could be due to two disabilities: 1) insulin production or/and 2) disability of the body to respond to insulin, either of which results in the increase of blood sugar. This epidemic disease is rapidly increasing in number and is considered as one of the main global health problems. Approximately 230 million individuals are suffering from diabetes around the world, and it has been predicted that the number of diabetic people will rise to about 300 million by the year $2025(1,2)$. Diabetes is divided into two types: type 1 is an insulin-dependent condition which is an autoimmune disease. Blood insulin level decreases due to damage to the pancreatic Beta cells which produce insulin by the attack of immune cells. Type 2 is an insulin-independent condition which is the result of resistance of the body to insulin. 90 to 95 percent of USA diabetic people are suffering from type 2 according to Wang et al. (3). The common synthetic drugs for diabetes are not popular because of the side effects, difficult regimen and high expenses, so the number of patients who tend to use folk treatments, especially medicinal plants, are increasing $(4,5)$. According to the World Health Organization (WHO) more researches are needed in the field of herbal treatment for diabetes (6).

Cynodon dactylon (C.d) is a member of the Poaceae family grown in Asia, Europe, Australia and Africa, and is also known as Bermuda grass. There are some reports indicating its medicinal potential. Antiviral, anti microbial, healing effects on urinary tract infection, syphilis, dysentery and prostatitis are being discussed in some reports (7). Kumar Singh et al. (7) reported an interesting impact of C.d on blood glucose level contributing to its antidiabetic and hypoglycemic activity. The main constituents of C.d are Glycerin, 9, 12-Octadecadienoyl chloride, Hexadecanoic acid which indicate its medicinal potential (8).

Electromagnetic field (EMF) has been proved to be therapeutically effective in a wide range of medical conditions. Antimicrobial, wound healing and neurological disorders are just some examples of this usage. Recently, some researches have been shown that indicate the anti diabetic and hypoglycemic effect of EMF. Tomonori Sakurai et al. (9) reported that a low frequency magnetic field increases the insulin se- 
cretion level from beta cells. Öcal et al. (10) reported the decrease of blood glucose level in the presence of an alternating magnetic field.

The present study was conducted to evaluate the influence of Cynodon dactylon, and magnetic field separately and a combination of them along with insulin. The determination of these effects has been studied on the diabetic mouse.

\section{Material and Methods}

\section{Treatment groups}

After obtaining the approval decision of law and bioethics committee of the Veterinary collage of Urmia University regarding the experiment, a total of 96 mice (Wistar strain) were subjected to the study in 12 groups, 8 mice for each group. The weights of mice were between 142 to 207 gram with the average weight of $175 \pm 2 \mathrm{gr}$. The first group was considered as control group and received nothing, the second group was the scheme group and received normal saline. The third and fourth groups were treated with $50 \mathrm{mgr} / \mathrm{Kg}$ of C.d extract, and the glucose levels in the third group were measured 5 minutes after administration while in the fourth group measurements were taken 60 minutes after injection. The reason for separating these two groups is prohibiting any increase of blood glucose because of stress due to secretion of adrenalin in the first blood collection from the tail vein. The fifth and $6^{\text {th }}$ groups received $100 \mathrm{mgr} / \mathrm{Kg}$ of $\mathrm{C} . \mathrm{d}$ extract and the glucose level in the fifth group were measured 5 minutes after administration of C.d and in the $6^{\text {th }}$ group it was measured 60 minutes after C.d administration. The $7^{\text {th }}$ group was injected by $0.5 \mu \mathrm{L} / \mathrm{Kg}$ insulin. The $8^{\text {th }}$ group was treated by insulin plus a first dose of the plant. The $9^{\text {th }}$ group was subjected to EMF treatment by a frequency of $110 \mathrm{KHz}$ and $700 \pm 20 \mathrm{mG}$. The $10^{\text {th }}$ group was treated by insulin injection and EMF exposure. The $11^{\text {th }}$ group was treated by a first dose of the plant and EMF exposure. Lastly, the $12^{\text {th }}$ group was subjected to the treatment by the three items: insulin, C.d and EMF. All the injections were intraperinoteal. Then animals were placed in separate cages in standard conditions at $22 \pm 2^{\circ} \mathrm{C}$ with a 12 light-dark cycle in which they had free access to pellet food and tap water during the experiment in the animal lab of the veterinary college of Urmia University.

\section{Induction of diabetes}

After adaptation of the mice to the environment, they had 24 hours fast. Then they were anesthetized by a combination of ketamine hydrochloride and xylazine hydrochloride. $60 \mathrm{mg} /$ $\mathrm{Kg}$ ketamine mixed with $10 \mathrm{mg} / \mathrm{Kg}$ xylazine and injected into all groups except the control group. The purpose of this combination was inducing diabetes in the mice rather than anesthesia. This mixture induces a sustained hyperglycemia Kawai et al. (11), Eun-Joo Park et al. (12). Their blood glucose levels were measured when they were anesthetized.

\section{Extract of C.d}

The root and stem of Cynodon dactylon were powdered and soaked in $70 \%$ ethyl alcohol (Mrec Co) and 30\% water for 48 hours in $24^{\circ} \mathrm{C}$, then filtered by Watman paper. Then the ex- tracts were obtained from a rotator device. The extracts were frozen and used as $100 \%$ alcoholic extract. Using normal saline, $0.5 \%$ extracts were prepared.

\section{Electromagnetic Field Application}

The EMF was generated by a DC power supply signal generator (made in PHYWE German). The generators generated a 2 phase square wave. The frequency was measured by a digital teslameter from a distance of $7.5 \mathrm{~cm}$ from the generator, and it was of $700 \pm 20 \mathrm{mG}$ intensity and frequency of 110 $\mathrm{KHz}$. In order to restrain the mice during the exposure time, a $30 \times 25 \times 20$ fiber box was made with no nails. Two $2 \times 2$ windows were placed in its wall. The mice were exposed to the EMF for 30 minutes one time.

\section{Blood sample collection}

After 5 minutes and then 60 minutes from the injection of C.d, blood samples were collected in order to screen the glucose level. Blood of the other groups were collected after 5 minutes of application of ketamine and xylazine, insulin or EMF. For that purpose blood was drawn from the rats' tail vein. Then, samples were analyzed for blood glucose levels by the glucometer apparatus to gather data. The glucometer apparatus was made in Germany from the Converjent (Elegance brand) factory.

\section{Statistical analysis}

The data were collected and analyzed by the variance method (ANOVA) and the significance range was considered as $p<0.05$. The groups which had significant differences were compared by Tukey and Bonferroni tests in order to compare the means. All of the analyses were carried out by SPSS package (Version 18).

\section{Results}

The results of the study are shown in Table 1. After induction of hyperglycemia by ketamine and xylazine, blood glucose levels were high in all groups, which generally is considered as Diabetic. The second group received normal saline and it did not have any effect on glucose levels after hyperglycemia induction. Blood glucose levels were measured after 5 minutes of C.d administration. The dose of $50 \mathrm{mg} / \mathrm{Kg}$ of C.d decreased the glucose level significantly. The blood glucose level dropped to the normal range, which is seen in the first group. The influence of the first dose of C.d after 5 minutes and insulin showed no significant difference on blood glucose level. The second dose $(100 \mathrm{mg} / \mathrm{Kg}$ ) lowered the glucose level significantly after 5 minutes, also. Although it affected the glucose level like insulin with no meaningful difference, it also had no significant difference with the second group which was diabetic. One hour after administering C.d, blood glucose levels were measured in other groups. The first dose maintained its effect. It did not have any significant differences with the control and insulin administrated groups, while there were significant differences between first dose after one hour and second group. The second dose lowered glucose level after one hour more than what it had after 5 minutes. The dif- 
Table 1. Effect of Cynodon dactylon, Electromagnetic Field, Insulin and their combination on blood glucose levels of mouse (mg/dL)

\begin{tabular}{|c|c|c|c|c|c|c|c|c|}
\hline Treatment Groups & 1 & 2 & 3 & 4 & 5 & 6 & 7 & 8 \\
\hline Controla $^{a}$ & 108 & 111 & 115 & 106 & 109 & 110 & 124 & 112 \\
\hline Normal Saline ${ }^{b}$ & 320 & 300 & 298 & 301 & 295 & 380 & 328 & 341 \\
\hline $\begin{array}{l}\text { C.d }(50 \mathrm{mg} / \mathrm{Kg}) \text { ac } \\
5 \text { Min after injection }\end{array}$ & 138 & 172 & 149 & 162 & 125 & 166 & 139 & 134 \\
\hline $\begin{array}{l}\text { C.d }(50 \mathrm{mg} / \mathrm{Kg})^{d} \\
60 \text { Min after injection }\end{array}$ & 103 & 107 & 119 & 113 & 108 & 117 & 120 & 109 \\
\hline $\begin{array}{l}\text { C.d }(100 \mathrm{mg} / \mathrm{Kg})^{\mathrm{a}} \\
5 \mathrm{Min} \text { after injection }\end{array}$ & 143 & 257 & 266 & 224 & 262 & 309 & 241 & 189 \\
\hline $\begin{array}{l}\text { C.d }(100 \mathrm{mg} / \mathrm{Kg})^{\text {af }} \\
60 \text { Minafter injection }\end{array}$ & 188 & 113 & 217 & 111 & 168 & 145 & 157 & 124 \\
\hline Insulin ${ }^{a}$ & 157 & 127 & 184 & 144 & 136 & 120 & 152 & 146 \\
\hline $\begin{array}{l}\text { Insulin }+ \\
\text { C.d }(50 \mathrm{mg} / \mathrm{Kg})^{d}\end{array}$ & 225 & 233 & 218 & 272 & 264 & 249 & 217 & 198 \\
\hline $\mathrm{EMF}^{\mathrm{d}}$ & 212 & 232 & 203 & 293 & 218 & 246 & 279 & 235 \\
\hline Insulin + EMF ae & 49 & 86 & 94 & 101 & 76 & 89 & 104 & 78 \\
\hline $\begin{array}{l}\text { EMF + C.d } \\
(50 \mathrm{mg} / \mathrm{Kg})^{\mathrm{df}}\end{array}$ & 223 & 235 & 242 & 198 & 218 & 186 & 163 & 179 \\
\hline $\begin{array}{l}\text { Insulin + } \\
\text { C.d }(50 \mathrm{mg} / \mathrm{Kg})^{\mathrm{a}} \\
+\mathrm{EMF}\end{array}$ & 108 & 102 & 98 & 113 & 118 & 114 & 106 & 121 \\
\hline
\end{tabular}

ference was not significant, but its effect after one hour was significantly different from the second group, while we did not see this difference in the first 5 minutes. The mixture effect of first dose of C.d and insulin was significant and it reduced the blood glucose level meaningfully. However, the mixture did not have a double effect, the mean level was significantly higher than the solely insulin and C.d administrated groups.

The EMF application significantly reduced the blood glucose level of mice. The EMF at this frequency lowered the glucose compared to the second group, but their glucose levels were still higher than the control and insulin injected groups. According to the data, the enhancer effect of EMF at this frequency was contemplated, so the combination of items were observed. The administration of insulin in the presence of EMF was significant, it reduced the blood glucose level to the normal range. The mean glucose levels of this group were lower than the control group. The point was that the blood glucose level in this group was significantly lower than the insulin only injected group.

The administration of C.d was also investigated in the presence of EMF. This combination also decreased the glucose level significantly. It was not as effective as the insulin or C.d injection solely. It seems that EMF reduces the effect of C.d or Insulin when they are injected alone. In contrast, C.d did not have any enhancing effect on the influence of EMF, since there was no significant difference between the EMF applied group and this group.
In the final treatment, C.d injection was accompanied by insulin administrated in the presence of EMF. This combination decreased the glucose level to the normal level as there were no differences in the glucose level. The mean results of the three mixture administration were lower than the mean results of C.d injected group and the group of insulin, without significant differences.

\section{Discussion}

According to data in the present study, C.d has a very effective influence on blood glucose level. C.d can decrease the blood glucose level in diabetic mice to the normal level. There are several studies indicating the same results, that C.d has antihyperglycemic effects on mice when it was used for diabetes treatment in folk medicine (13). Kumar Singh et al. (7) studied the ethanolic extract of C.d in normal and streptozotocin-induced diabetic rats in three doses of 250,500 and $750 \mathrm{mg} / \mathrm{Kg}$ by oral administration. They found that all the dosages have a significant effect in reducing glucose level. The most effective dosage was $500 \mathrm{mg} / \mathrm{Kg}$, which dropped glucose level by $42.12 \%$ for normal mice and $43.42 \%$ for diabetic mice. In this study, the most effective dose was $50 \mathrm{mg} / \mathrm{Kg}$, with a sustained effect. The difference in the dosage effects could be due to different administrations, oral and IP injection. Some of the bioactive substances in C.d can be broken down through the digestive system in oral administration and as a result higher dosages are needed for more effect. The fact that some plants have more antihyperglycemic effects in lower dosage than the higher one is a common phenomenon in herbal nature. For instance C.d in the mentioned and present study, Peganum Harmala Mohammad Nezhady et al. (14) and Vinca rosea Chattopadhyay et al. (15). In an another study, Jarald et al. (16) investigated polysaccharide and non-polysaccharide fractions of an aqueous extract of C.d on glucose overloaded and alloxan-induced diabetic rats by oral administration. They found that $400 \mathrm{mg} / \mathrm{Kg}$ of non-polysaccharide fractions have a significant effect on blood glucose levels. Also, they studied the insulin level, which did not increase during the C.d administration. This fact indicates that C.d does not have a secondary effect and it does not affect glucose level by increasing the insulin level. It seems that C.d has an insulin-like effect in reducing blood glucose level. By the aforementioned studies and that found in the present study, it can be concluded that C.d has a meaningful reducing effect on glucose level and it can be considered as an alternative medication for diabetes mellitus.

There are many evidences supporting the hypoglycemic ability of magnetic field exposure, but the optimum frequency and exposure time remain unclear (17-21). Öcal et al. (10) investigated the effect of $5 \mathrm{mT}$ and $8 \mathrm{mT}$ on healthy and diabetic rats for the duration of 165 minutes for three weeks. They found that alternating magnetic field decreases the blood glucose level in both healthy and diabetic rats. Eghdami et al. (19) reported that the blood glucose level of mice, who were subjected to a field of $25 \mathrm{~Hz}$ and intensity of $250 \mu \mathrm{T}$ for 45 minutes for 2 weeks, is decreased more efficienlyt than with metphormine and insulin. Sieroń et al. (4) evaluated the 
marked glucose by ${ }^{3} \mathrm{H}$ uptake in organs and tissues of rat in the exposure to an extremely low electromagnetic field. They subjected the rats to the electromagnetic field with frequency of $10 \mathrm{~Hz}$ and intensity of 1.8-3.8 $\mathrm{mT}$ for one hour in 14 days. The results of radioactivity of $\left[{ }^{3} \mathrm{H}\right]$ glucose showed that glucose uptake was significantly higher in the liver, kidney, heart muscle, cartilage, connective tissue, skin and tendon compared to the control group. They suggested that Extremely Low EMF (ELEMF) can facilitate transportation of glucose through the cell membrane. Sakurai et al. (9) worked on hamster-derived insulin secreting cells (TIH-T15) to investigate the effect of ELEMF on them. The cells were exposed to an ELEMF freq with a frequency of $60 \mathrm{~Hz}$ and intensity of $5 \mathrm{mT}$. Cell numbers were increased during 5 days of exposure in the absence of glucose, while the exposure for 5 days in the presence of $100 \mathrm{mg} /$ $\mathrm{dL}$ glucose and for 2 days in the absence of glucose, increased the insulin secretion. Also they found that ELEMF increased the concentration of intracellular insulin in the cell lines.

\section{Conclusion}

According to the results of this study, it could be concluded that Cynodon dactylon can be considered as a good alternative medication for diabetes mellitus, also EMF has an impact on the blood glucose level of diabetic mice. For determination of an optimum dosage of C.d and frequency and exposure duration of EMF further studies are required.

\section{Conflict of Interest}

No conflict of interest was declared by the authors.

\section{References}

1. Pandikumar $\mathrm{P}, \mathrm{Babu} N \mathrm{~N}$, Ignacimuthu S. Hypoglycemic and antihyperglycemic effect of Begonia malabarica Lam. in normal and streptozotocin induced diabetic rats. J Ethnopharmacol 2009;124:111-5. [CrossRef]

2. Li F, Zhang Y, Zhong Z. Antihyperglycemic effect of ganoderma lucidum polysaccharides on streptozotocin-induced diabetic mice. Int J Mol Sci 2011;12:6135-45. [CrossRef]

3. Wang L, Zhang XT, Zhang HY, Yao HY, Zhang H. Effect of Vaccinium bracteatum Thunb. leaves extract on blood glucose and plasma lipid levels in streptozotocin-induced diabetic mice. J Ethnopharmacol 2010;130:465-9. [CrossRef]

4. Sieroń A, Brus H, Konecki J, Cieślar G, Szkilnik R, Nowak P, et al. Effect of Low Frequency Electromagnetic Fields on [3H]Glucose Uptake in Rat Tissues. Polish J of Environ Stud 2007;16:309-12.

5. Chen XH, Bai X, Liu YH, Tian LY, Zhou JQ, Zhou Q. Anti-diabetic effects of water extract and crude polysaccharides from tuberous root of Liriope spicata var. prolifera in mice. J Ethnopharmacol 2009;122:205-9. [CrossRef]

6. Gray AM, Abdel-Wahab YH, Flatt PR. The traditional plant treatment, Sambucus nigra (elder), exhibits insulin-like and insulinreleasing actions in vitro. J Nutr 2000;130:15-20.

7. Singh SK, Kesari AN, Gupta RK, Jaiswal D, Watal G. Assessment of antidiabetic potential of Cynodon dactylon extract in streptozotocin diabetic rats. J Ethnopharmacol 2007;114:174-9. [CrossRef]

8. Shabi MM, Gayathri K, Venkalakshmi R, Sasikala C. Chemical constituents of hydro alcoholic extract and phenolic fraction of Cynodon dactylon. Int J Chem Tech Res 2010;2:149-54.

9. Sakurai T, Yoshimoto M, Koyama S, Miyakoshi J. Exposure to extremely low frequency magnetic fields affects insulin-secreting cells. Bioelectromagnetics 2008;29:118-24. [CrossRef]

10. Ocal I, Kalkan T, Günay $\mathrm{I}$, Effects of alternating magnetic field on the metabolism of the healthy and diabetic organisms. Braz Arch Biol Technol 2008;51:523-30.

11. Kawai N, Stummer W, Ennis SR, Betz AL, Keep RF. Blood-brain barrier glutamine transport during normoglycemic and hyperglycemic focal cerebral ischemia. J Cereb Blood Flow Metab 1999;19:79-86. [CrossRef]

12. Park EJ, Dodds J, Smith NB. Dose comparison of ultrasonic transdermal insulin delivery to subcutaneous insulin injection. Int $\mathrm{J}$ Nanomedicine 2008;3:335-41.

13. Kirtikar KK, Basu BD, Indian Medicinal Plants. 2nd edition, Lalit Mohan Publication, India, 1980;2650.

14. Nafisi S, Asghari MH, Mohammad Nezhady MA., Ekhtiari MS. Possible antidiabetic effect of peganum harmala on streptozocineinduced mouse. World Applied Sciences Journal 2011;14:822-4.

15. Chattopadhyay RR, Sarkar SK, Ganguly S, Banerjee RN, Basu TK. Hypoglycemic and antihyperglycemic effect of leaves of Vinca rosea linn. Indian J Physiol Pharmacol 1991;35:145-51.

16. Jarald EE, Joshi SB, Jain DC. Antidiabetic activity of aqueous extract and non polysaccharide fraction of Cynodon dactylon Pers. Indian J Exp Biol 2008;46:660-7.

17. Havas M. Electromagnetic hypersensitivity: biological effects of dirty electricity with emphasis on diabetes and multiple sclerosis. Electromagn Biol Med 2006;25:259-68. [CrossRef]

18. Havas M. Dirty electricity elevates blood sugar among electrically sensitive diabetics and may explain brittle diabetes. Electromagn Biol Med 2008;27:135-46. [CrossRef]

19. Eghdami $A$, Piry $H$, Jafari $H$, Sirati $M$, Jahani Hashemi $H$, Khabbaz F. Effect of Electromagnetic Field on Male Diabetic Bulb/C Mice Induced by Streptozocin (STZ). Supplementary issue, Vol. 36, No.1, 2007.

20. Sakurai T, Satake A, Sumi S, Inoue K, Miyakoshi J. An extremely low frequency magnetic field attenuates insulin secretion from the insulinoma cell line, RIN-m. Bioelectromagnetics 2004;25:160-6. [CrossRef]

21. Graak V, Chaudhary S, Bal BS, Sandhu JS. Evaluation of the efficacy of pulsed electromagnetic field in the management of patients with diabetic polyneuropathy. Int J Diabetes Dev Ctries 2009;29:56-61. [CrossRef] 